Focussed on "Crack Paths"

\title{
Influence of microstructure on fatigue property of ultra high-strength steels
}

\author{
Kanji Okuda, Kazuhiro Ogawa, Yuji Ichikawa \\ Tohoku University, Japan \\ kanji.okuda@rift.mech.tohoku.ac.jp,kogawa@rift.mech.tohoku.ac.jp, ichikawa@rift.mech.tohoku.ac.jp
}

Tsuyoshi Shiozaki, Naoki Yamaguchi

JFE Steel Corporation, Japan

t-shioraki@jffe-stel..co.jp,n-yamaguchi@jffe-steel.co.jp

ABSTRACT. Ultra-high-strength steels (with tensile strength higher than 980 $\mathrm{MPa}$ ) are widely used in automobile manufacturing owing to their lightweight that contributes to fuel efficiency. The fatigue strength of ultra-high-strength steels with a notch tends to decrease, which is known as the effect of notch sensitivity. In this study, 4-point bending fatigue tests were performed to examine the fatigue strength and notch sensitivity of four steels; namely 590 $\mathrm{MPa}$ class steel, $980 \mathrm{MPa}$ class martensitic steel, $980 \mathrm{MPa}$ class bainitic steel, and $980 \mathrm{MPa}$ class precipitation hardening steel plates with three different stress concentration factors. The results indicate that the fatigue strength and notch sensitivity of $980 \mathrm{MPa}$ class steel specimens were higher than those of $590 \mathrm{MPa}$ class steel specimens. The notch sensitivities of tested plate specimens were lower than those reported for cylindrical specimens of bainitic ultra-high-strength steels. Fatigue crack observation revealed that the cracks initiated in $590 \mathrm{MPa}$ class steel, $980 \mathrm{MPa}$ class bainitic, and martensitic steel propagated vertically from the lowest bottom of notch. Although similar initial crack propagation pattern was detected in precipitation hardening steel, the crack changed direction when it reached the central part of the specimen.

KEYWORDS. Ultra-high-strength steel; Fatigue; 4-point bending; Fatigue crack.

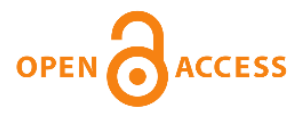

Citation: Okuda, K., Ogawa, K., Ichikawa, Y., Shiozaki, T., Yamaguchi, N., Influence of microstructure on fatigue property of ultra high-strength steels, Frattura ed Integrità Strutturale, 48 (2019) 125-134.

Received: 30.11 .2019

Accepted: 18.02 .2019

Published: 01.04.2019

Copyright: (C) 2019 This is an open access article under the terms of the CC-BY 4.0, which permits unrestricted use, distribution, and reproduction in any medium, provided the original author and source are credited.

\section{INTRODUCTION}

ecently, automobile fuel efficiency has been receiving worldwide attention to reduce automotive carbon emissions and to surpress global warming. Reducing the vehicle weight is one of the most efficient methods to improve fuel efficiency. Hence, this can be achieved by adopting lightweight steel with higher strength. For example, a similar 
performance can be obtained with $1 / 3$ of the vehicle weight using three times stronger lightweight steel than conventional steel.

Ultra-high-tensile-strength steel (UHTS) exhibits lightweight properties with relatively high tensile strength, higher than $980 \mathrm{MPa}$, compared to conventional mild steel with tensile strength of approximately $300 \mathrm{MPa}$. Multiple methods can be used to enhance the tensile strength of steels, such as heat treatment and microstructural control. These methods allow producing UHTS with varying properties, including extension rates and yield stress values.

However, despite the high fatigue strength of UHTS compared to conventional steel, its applications in vehicle parts are limited owing to the significant decrease in UHTS fatigue strength when it is subjected to any stress concentration. The fatigue strength of UHTS used in fillet welded joint has shown a behavior similar to that of conventional steel because of the high stress concentration factor between the welded metal and substrate. Using UHTS in lap fillet joint of a suspension frame is critical owing to the limitation of producing it using butt welding; however, UHTS may be susceptible to large vibrations owing to the position of suspension frames.

The reduction in fatigue strength caused by stress concentration is known as notch sensitivity. This fatigue property is inherent to each material. Notch sensitivity is quantified by the fatigue notch factor $K_{f}$, defined as

$$
K_{f}=\frac{S_{c}}{S_{N}}
$$

where $S_{C}$ is the fatigue limit of smooth specimen and $S_{N}$ is the fatigue limit of notched specimen [1].

Notch sensitivity is generally evaluated using cylindrical specimens. The evaluations have revealed that the higher strength steel typically exhibits higher notch sensitivity. Fig. 1, which shows the notch sensitivity of cylindrical carbon steel with different strengths in rotating bending fatigue test [2], indicates that the notch sensitivity of UHTS is seen to be higher than that of a $787 \mathrm{MPa}$ class specimen. Also, Fig. 1 shows that $K_{f}$ increases at a rate proportional to stress concentration factor $K_{t}$ up to 2. Similar trend was observed in the latest bainitic UHTS [3]. Then, $K_{f}$ values become almost stagnant as the $K_{t}$ value increases. Notch sensitivity must be considered when using high-strength material in parts subjected to stress concentration because the value of $K_{f}$ for high-strength materials tends to increase to approx. 3 . However, most of the notch sensitivity evaluations described above are obtained by a rotary bending fatigue test. Rotating bending test requires a cylindrical specimen which is not feasible make out of steel sheets that are used in automobiles. Thus, any difference in notch sensitivity related to the shape of the specimen must be considered to determine the appropriate design. In this design stage, the fatigue notch factor is determined and the fatigue characteristics are evaluated using a thin steel plate sample. In particular, when a high-strength material like UHTS with high notch sensitivity is used for automobile parts using thin steel plates, its fatigue characteristics must be evaluated using a thin steel plate specimen with the existence of a stress concentration.

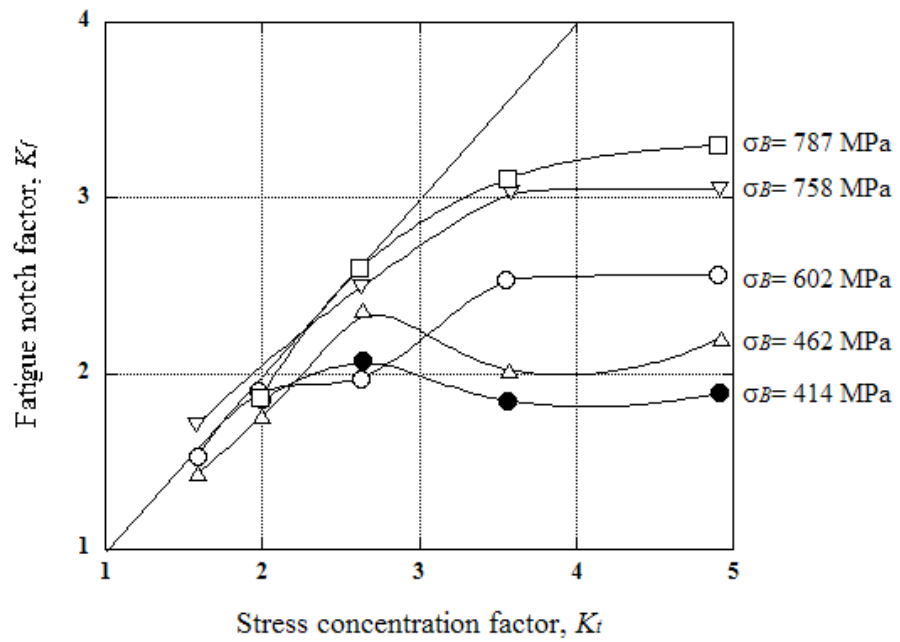

Figure 1: Relationship between $K_{t}$ and $K_{f}$ of carbon steels with different tensile strengths [2].

The microstructure of materials must be considered in order to evaluate their fatigue properties because the crack propagation behavior and fatigue strength can be changed based on the microstructural changes [4 6]. However, many studies aimed at improving the fatigue strength of welded joints focused on the development of residual stresses induced 
by hammer peening [7] or shot peening [8] as methods to improve fatigue strength. However, in recent years, new UHTS with different microstructures are developed to improve fatigue strength of UHTS by microstructural control.

Thus, further studies are required to evaluate the fatigue properties of UHTS welded joints with different microstructures. In this study, fatigue tests and crack observations have been performed to evaluate the fatigue properties of UHTSs and ultimately improve the fatigue properties of steels.

In order to improve the fatigue characteristics of UHTS plates with different tensile strengths and microstructures were evaluated using flat specimens with notches simulating the stress concentration factor at the toe of the overlap fillet joint.

\section{EXPERIMENTAL PROCEDURE}

\section{Materials and specimens}

urface notch specimens, which simulate lap fillet joint, and smooth specimens were used in this study. Current $\mathrm{S}$ material (590 MPa class ferrite-bainitic steel), and 3 types of UHTS (980 MPa class bainitic steel, $980 \mathrm{MPa}$ class martensitic steel, and $980 \mathrm{MPa}$ class precipitation hardening steel) are prepared for the fatigue test. Fig. 2 shows microstructures of 4 types of steels. Bainitic steel has low ratio of martensitic phase inside bainitic based steel, while martensitic steel consists of full martensitic phase. Precipitation hardened steel of this study was a precipitate of nano-sized particles in full-ferrite steel. The mechanical properties of the tested steels are listed in Tab. 1.

\begin{tabular}{ccccc}
\hline Steels & $\begin{array}{c}\text { Tensile Strength } \\
{[\mathrm{MPa}]}\end{array}$ & Yield Stress [MPa] & Elongation [\%] & $\begin{array}{c}\text { Vickers Hardness } \\
{[\mathrm{HV} 1 \mathrm{~kg}]}\end{array}$ \\
\hline 590 MPa class steel & 610 & 464 & 26.0 & 192 \\
Bainitic steel & 988 & 860 & 15.0 & 307 \\
Martensitic steel & 1095 & 1008 & 11.1 & 356 \\
$\begin{array}{c}\text { Precipitation } \\
\text { hardened steel }\end{array}$ & 1059 & 1014 & 17.6 & 333 \\
\hline
\end{tabular}

Table 1: Mechanical properties of four types of steel.
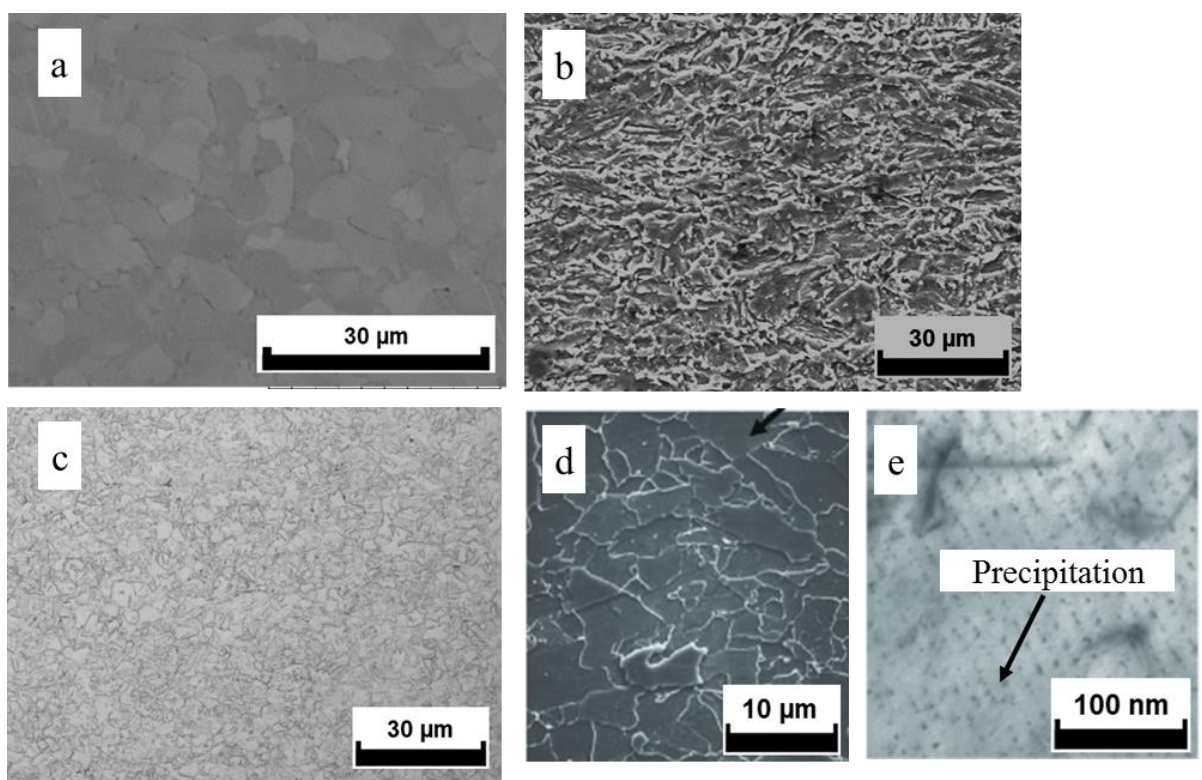

Figure 2: Microstructures of 4 types of steels (a) $590 \mathrm{MPa}$ class steel, (b) bainitic steel, (c) martensitic steel, (d) and (e) precipitation hardened steel [9].

Fig. 3 shows the sizes of fatigue test specimens. The notch depth is $1 \mathrm{~mm}$, and the bottom of notch was processed with a curvature radius of $0.1 \mathrm{~mm}$ or $0.2 \mathrm{~mm}$. The stress concentration factor of lap fillet joint in suspension frame, shown in Fig. 
4, which had been estimated using finite element method, was approximately 2-3 using 1/4 sized model described in Fig. 5. Each samples notch was prepared with a stress concentration higher than that of a general lap fillet.. Thus, $K_{t}$ values of 2.6, and 3.6 were obtained for the specimens with the curvature radii of the notch bottom $0.2 \mathrm{~mm}$ and $0.1 \mathrm{~mm}$, respectively. Surfaces of smooth specimens were electro-polished to eliminate or reduce the roughness. Finite element analysis has been performed to calculate stress concentration factor of welded joint and surface notch specimen using NASTRAN. Pulsating load-controlled 4-point bending fatigue tests were conducted with stress ratio $\mathrm{R}=0(10-14 \mathrm{~Hz})$. The definition of fracture was of $0.25 \mathrm{~mm}$ deformation. Cyclic tests were stopped when the cross-head displacement reaches $0.25 \mathrm{~mm}$ or the number of cycles reaches $3 \times 10^{6}$. The stress range of non-fractured specimens under $3 \times 10^{6}$ cycles was used as fatigue limit to calculate the fatigue notch factor $K_{f .}$. The strain value was measured at 2000 cycles each points using strain gage.

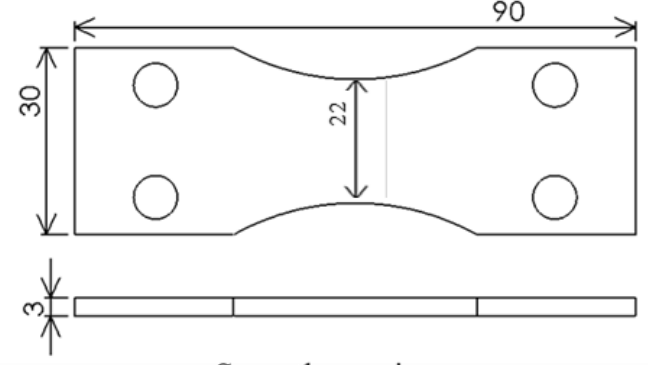

Smooth specimen

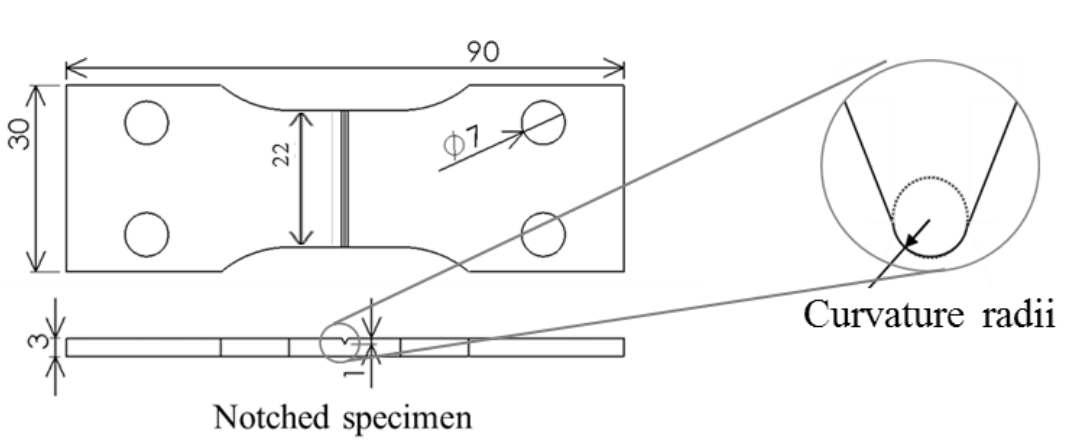

Figure 3: Sizes of tested specimens (mm).

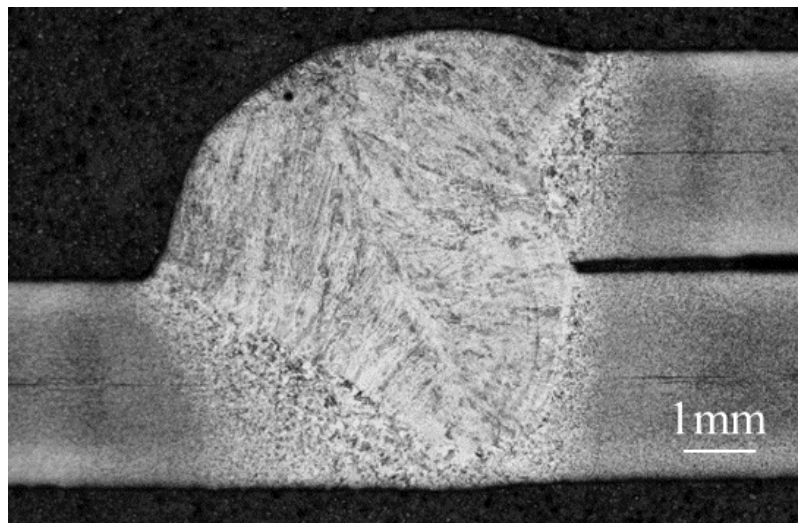

Figure 4: Cross section image of lap fillet joint supposed in this study.
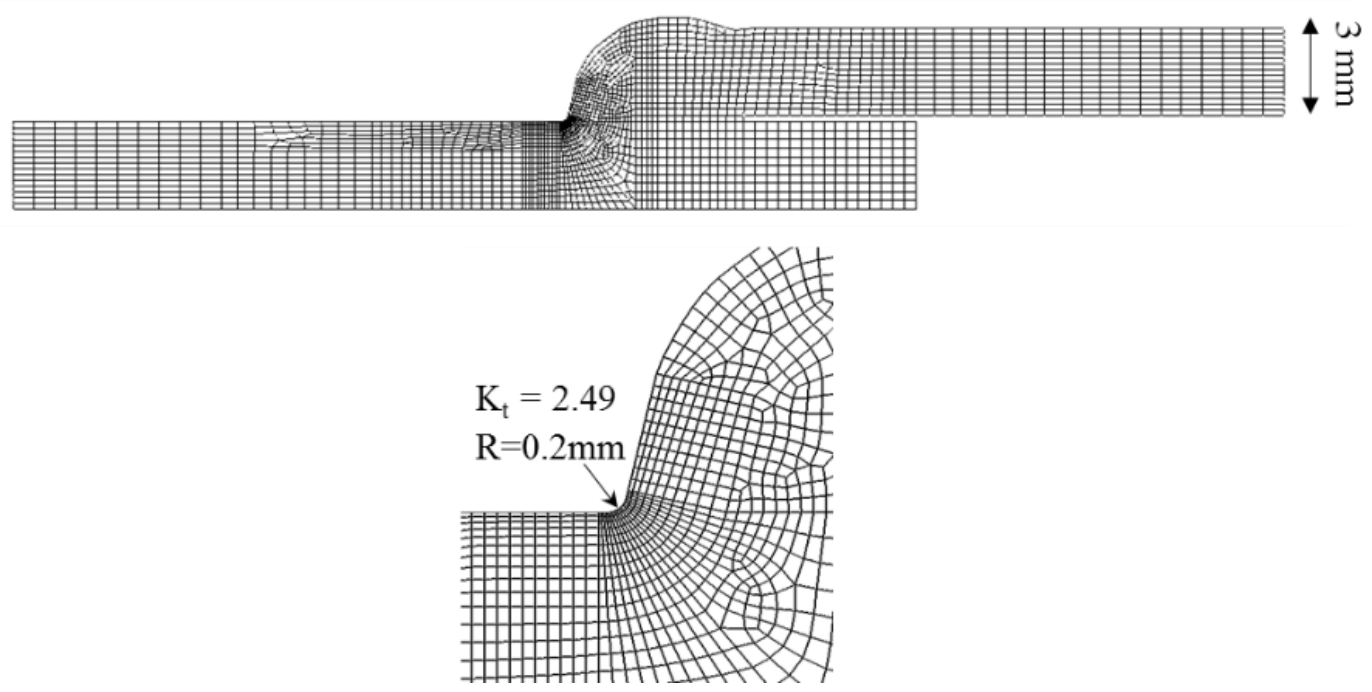
Fatigue tests

Figure 5: Model used for FEM calculation.

The fatigue test results are shown in Fig. 3. The fatigue limits when $K_{t}=1$ for all of the steel specimens are almost equivalent to their tensile strengths. The fatigue strength of notched specimens decreased with increasing stress concentration factor. However, the fatigue strength of notched $980 \mathrm{MPa}$ class steel specimen was higher than that of notched $590 \mathrm{MPa}$ class steel specimen. Though similar fatigue strength were obtained for notched bainitic steel and martensitic steel specimens, the precipitation hardening steel is approximately 100-150 MPa stronger than either of those steels. This result indicates the significant effect of microstructure on the fatigue strength of steels.

The fatigue limit of precipitation hardening steel when $K_{t}=3.6$ was estimated as $500 \mathrm{MPa}$. The estimated fatigue limit value with the data obtained from the fatigue test were used to calculate the notch sensitivities of all the tested specimens, as shown in Fig. 4. The notch sensitivities of the steel plates were far lower than those of cylindrical specimens. This can be attributed to the shape of surface notch specimen with one-side notch, and easiness of trapping of retention cracks. Materials with high stress gradient is known to be easy to retain crack of crack tip [10]. Steel plate with $3 \mathrm{~mm}$ thickness in this study has high stress gradient compared to conventional cylindrical specimens with $10 \mathrm{~mm}$ diameter used for evaluation of relationship between $K_{t}$ and $K_{f}[2]$.
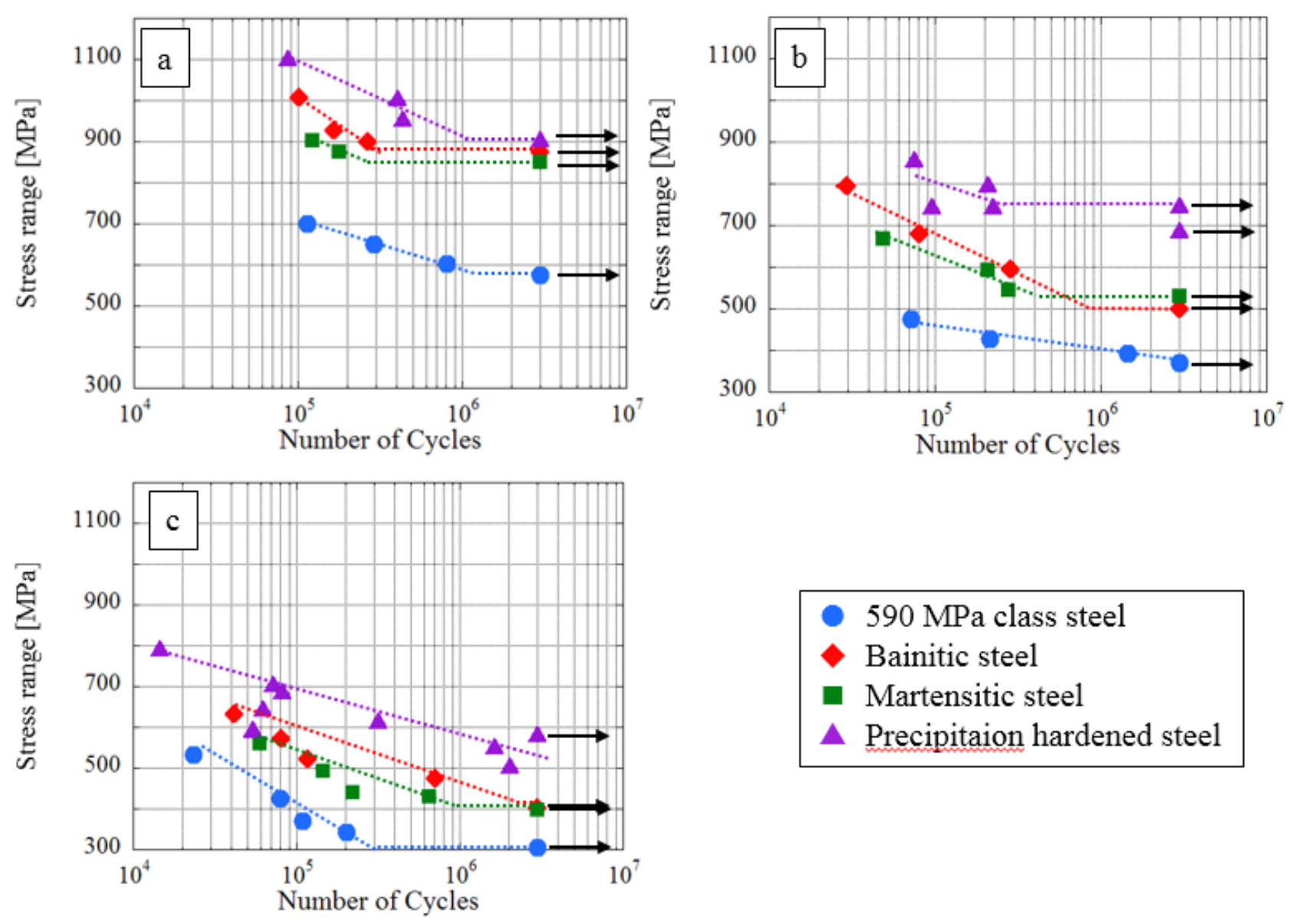

Figure 6: Influence of specimen dimensions on fatigue strength (a) $K_{t}=1$, (b) $K_{t}=2.6$, (c) $K_{t}=3.6$.

\section{Evaluation of data of strain gage}

In order to elucidate the cause of high fatigue strength of precipitation hardened steel, evaluation on strain gage data was conducted. The measured results by strain gage against the number of cycles in Fig. 8 indicated that crack propagation which initiated at A, continued to propagate until the sample finally fractured at B. A is defined as the first point when the gradient (calculated by the least square method) of the last 6000 cycles were lower than 0 , a value which was calculated from adjacent data point, starting from the fracture point, $\mathrm{B}$ to $\mathrm{A}$. 


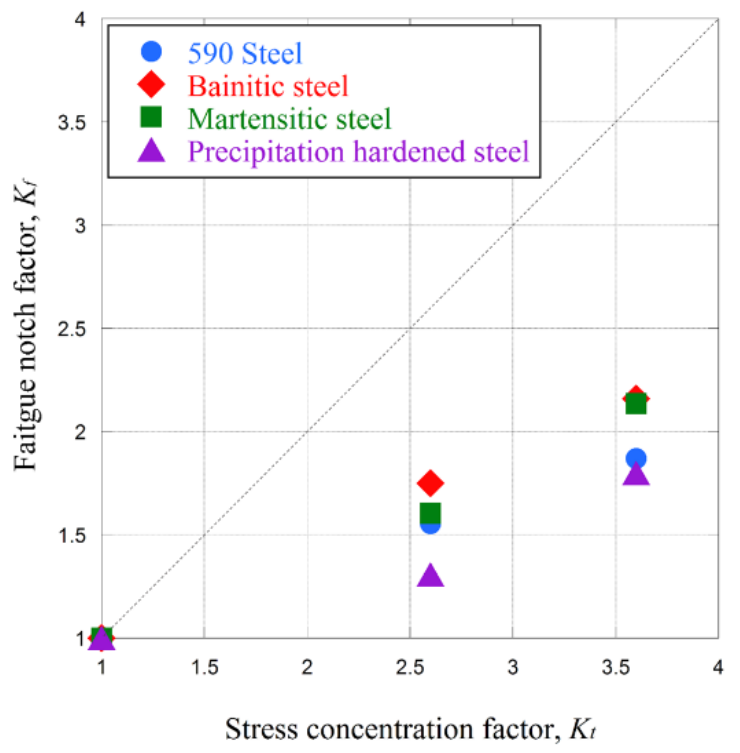

Figure 7: Relationship between $K_{t}$ and $K_{f}$ of tested specimens.

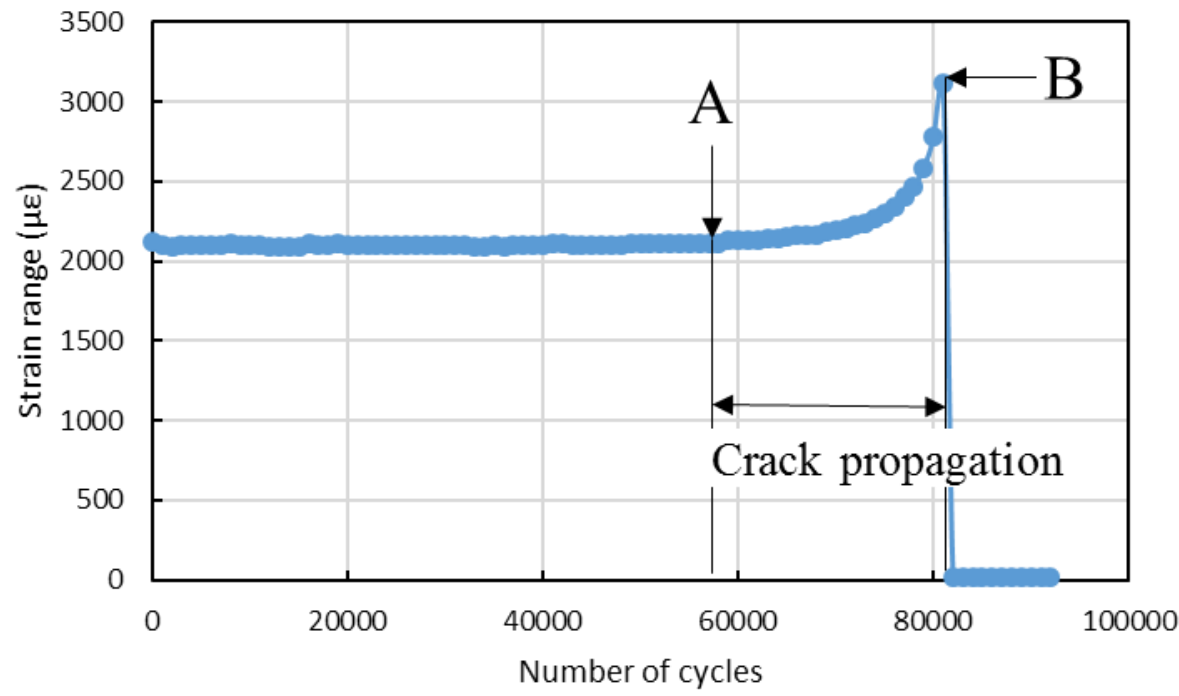

Figure 8: Measured data of strain gage with increasing number of cycles (Precipitation hardened steel (688 kN, 82023 fraction)

Fig. 9 shows the S-N curves of the test samples from beginning of the test until A. The results shown the crack propagation occurred faster for the precipitation hardened steel samples, then followed by bainitic steel samples and martensitic steel samples, respectively. These results were coherent with the S-N curves shown in Fig. 6. As a results, the precipitation hardened steel samples had shown high fatigue strength attributed to the numerous nano-sized precipitates inside its grains, which intercept the movement of dislocation required for crack generation.

Fig. 10 shows the S-N curves of the same test samples used in Fig. 9, but from A to B, representing the length of crack propagation of each samples. Coherent to results obtained in Fig. 9, the cycle range of crack propagation of precipitation hardened steel was the slowest, followed by bainitic steel and martensitic steel.

To elucidate the cause of delay in crack propagation speed in precipitation hardened steel, SEM observation and EBSD analysis was conducted.

\section{SEM observation and EBSD analysis of cracks}

Fig. 11 indicates the scanning electron microscope (SEM) images of fatigue crack growth in each specimen when $K_{t}=2.6$. The fatigue cracks initiated in $590 \mathrm{MPa}$ class steel, $980 \mathrm{MPa}$ class bainitic steel, and martensitic steel specimens propagated 
vertically from the bottom of notch. Meanwhile, a similar initial propagation pattern was detected for the crack initiated in the precipitation hardening steel specimen; however, secondary cracks branched out in opposite directions when it reached the central part of the specimen. The cracks initiated in the $980 \mathrm{MPa}$ class bainitic steel and martensitic steel specimens propagated straight from the bottom of notch. However, the curve of fatigue crack of precipitation hardening steel intercepted the crack propagation by spreading the energy of repeated stress. In order to observe the resulting microstructural changes and eventually understand the crack propagation mechanism that caused the fatigue crack, an electron back scattered diffraction (EBSD) analysis was conducted. Figs. 12 and 13 illustrated the results of EBSD analysis performed for five crack points that initiated in the precipitation hardening steel specimen.
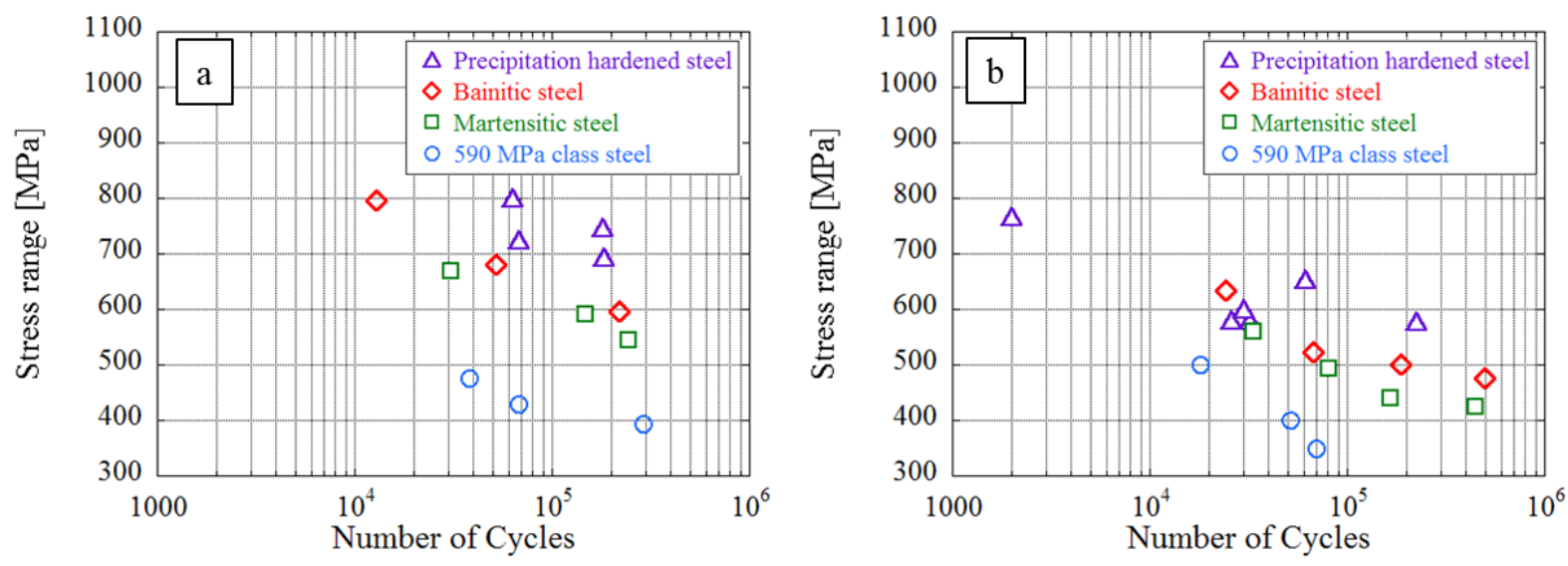

Figure 9: S-N curves of crack propagation start
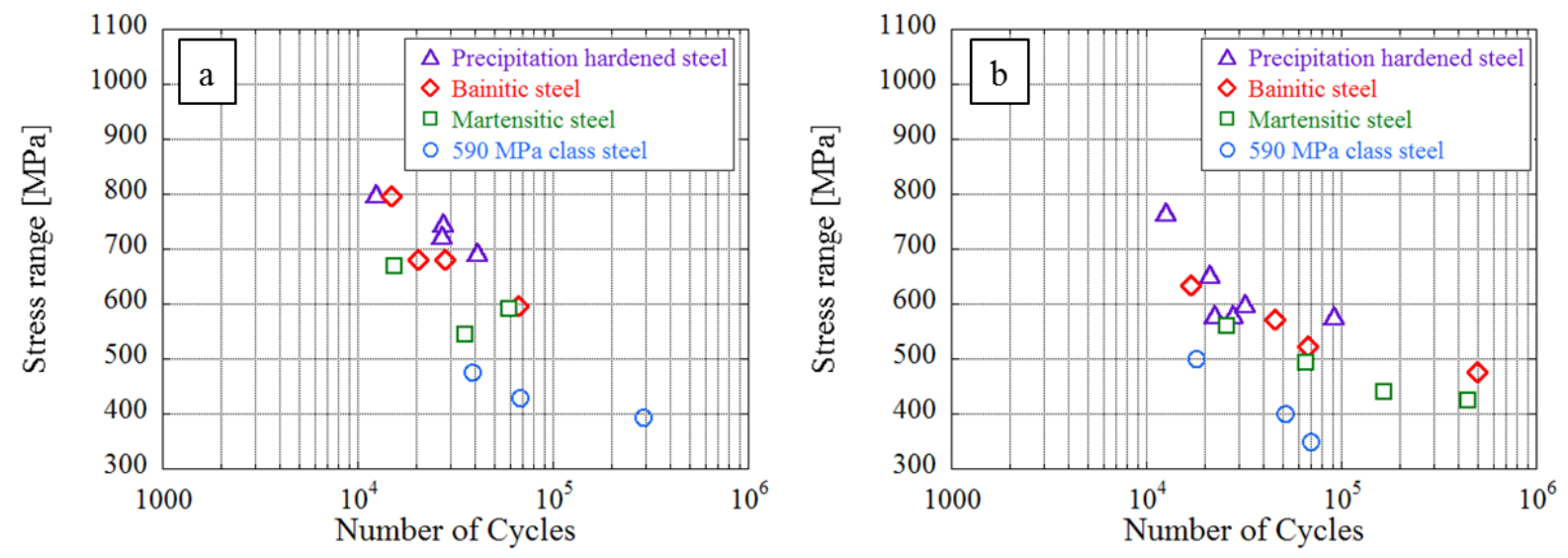

Figure 10: S-N curves of cycle range of crack propagation

EBSD analysis revealed the fatigue crack characteristics of each steel. A linear crack growth pattern with numerous repeated small refractions was observed in the $590 \mathrm{MPa}$ class steel specimen. The crack propagation direction may change and grow in grains when the crack propagates into adjacent crystal grain with different orientation, such as Grain A shown in Fig. 12. Meanwhile, the EBSD analysis of $980 \mathrm{MPa}$ class bainitic steel specimen revealed a nearly vertical crack propagation pattern with repeated small branches and refractions from the bottom of notch; however, some of these refractions were intercepted by certain grains such as Grain B shown in Fig. 12. Based on the SEM observations carried out after etching, it was confirmed that this crystal grain was a martensitic phase. The fracture morphology formed during crack propagation in the $980 \mathrm{MPa}$ class martensitic steel specimen was of transgranular character. When the crack changed its direction in the 980 $\mathrm{MPa}$ precipitation hardening steel specimen, the fracture morphology also changed. Since nano-sized precipitation strengthen the ferrite grains in the precipitation hardened steel, the intergranular strength is relatively weaker than that of transgranular. Hence, the transgranular crack was observed. Detailed EBSD analysis of the precipitation hardening steel specimen is shown in Fig. 13. The arrow indicates the direction of fatigue crack propagation. Point b is an enlarged image of the crack between the bottom of notch and its branch point, where the fatigue crack grew with transgranular fracture. Point $\mathrm{c}$ shows the intergranular fracture occurred when the crack propagated in the longitudinal direction after the crack 
branch was formed. The crack may change its direction in vertical direction of specimen, as shown in Point d, at which transgranular fracture morphology was detected while the crack propagated vertically. A fracture morphology of intergranular character was observed at Point e at the end of crack. This indicates that the fracture morphology is influenced by microstructural control technique, which may delay the crack propagation range of material. Fig. 14 indicates the result of EBSD analysis near the point $b$ in Fig. 13. Before the crack reaches the branch point, many small cracks propagates in horizontal direction. The fracture morphology of the small crack was of transgranular character. These small cracks is also considered to spread the energy of repeated stress. Furthermore, concerning the refraction of the crack, it is considered that the crack tip is blunted due to the sliding deformation of the slant crack [11].
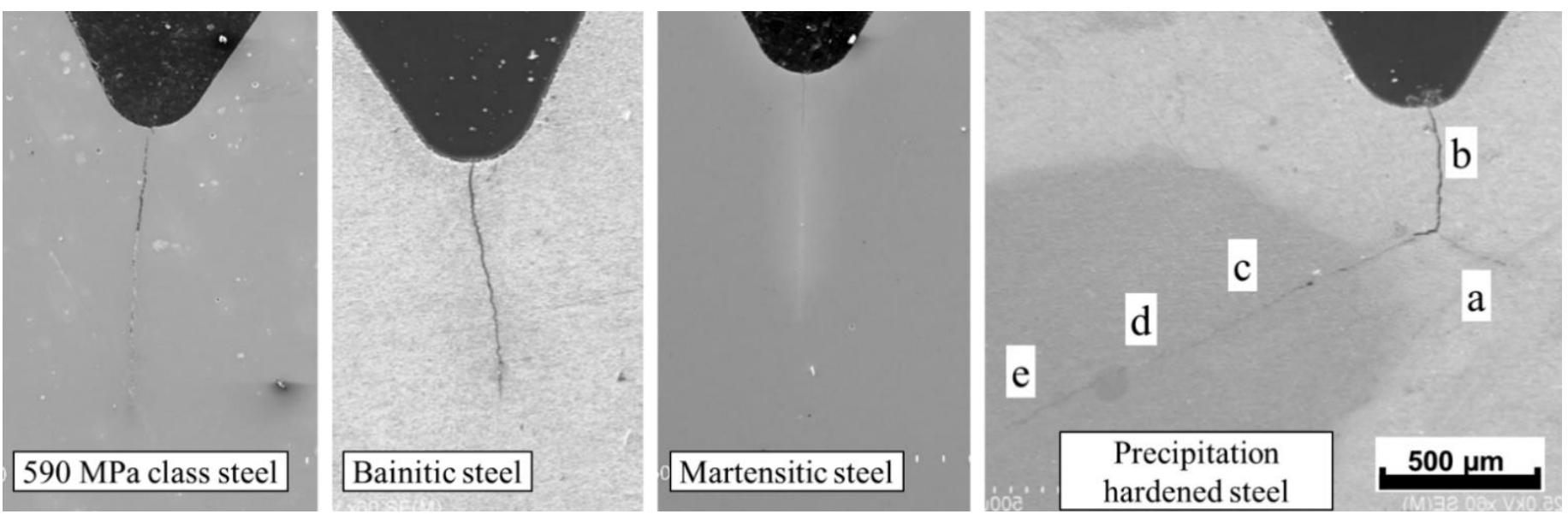

Figure 11: SEM images of fatigue cracks growth.

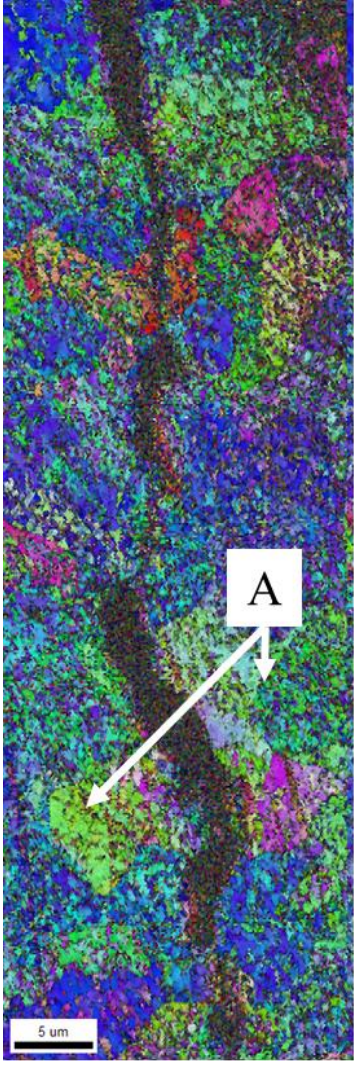

$590 \mathrm{MPa}$ class steel

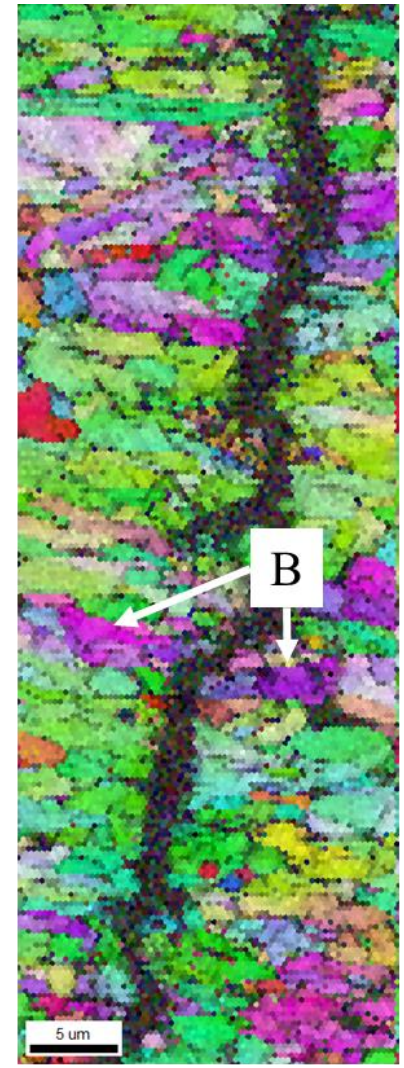

Bainitic steel

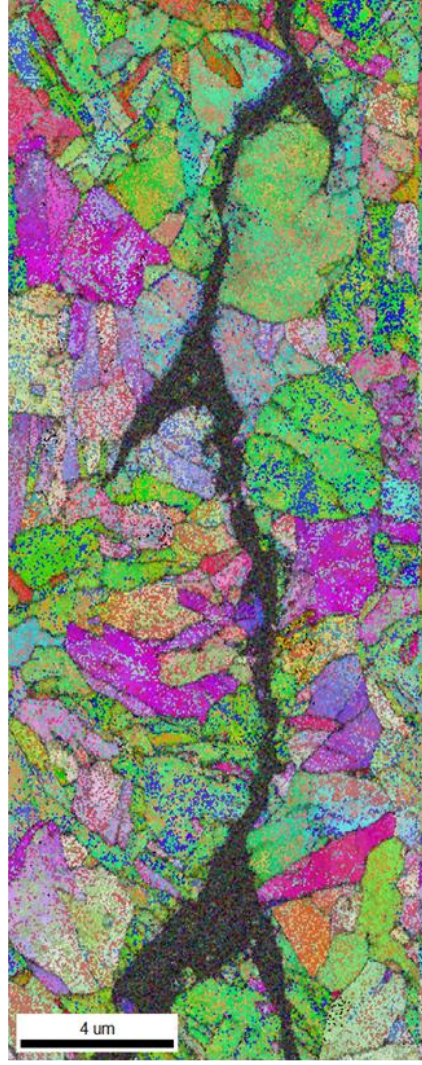

Martensitic steel

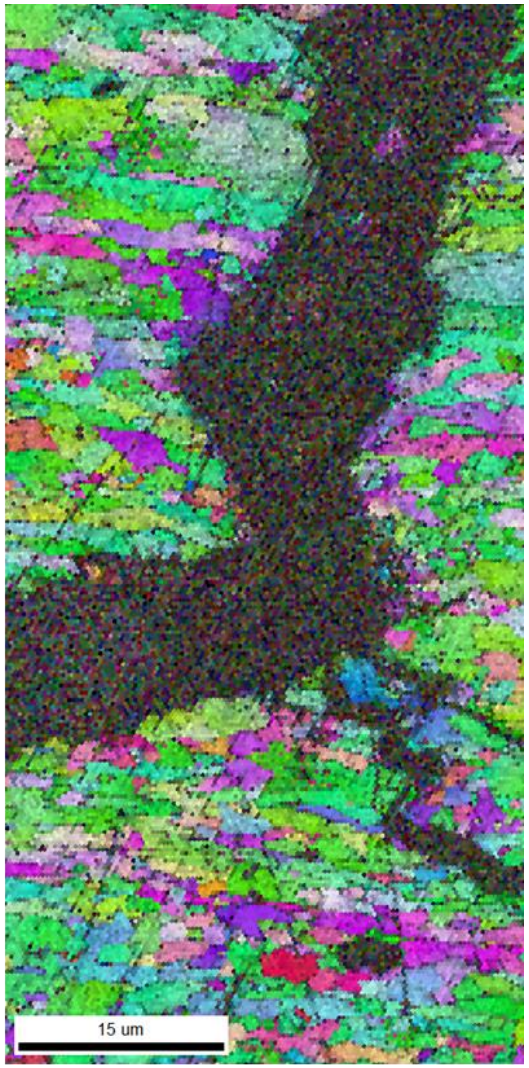

Precipitation hardened steel

Figure 12: Results of EBSD analysis. 

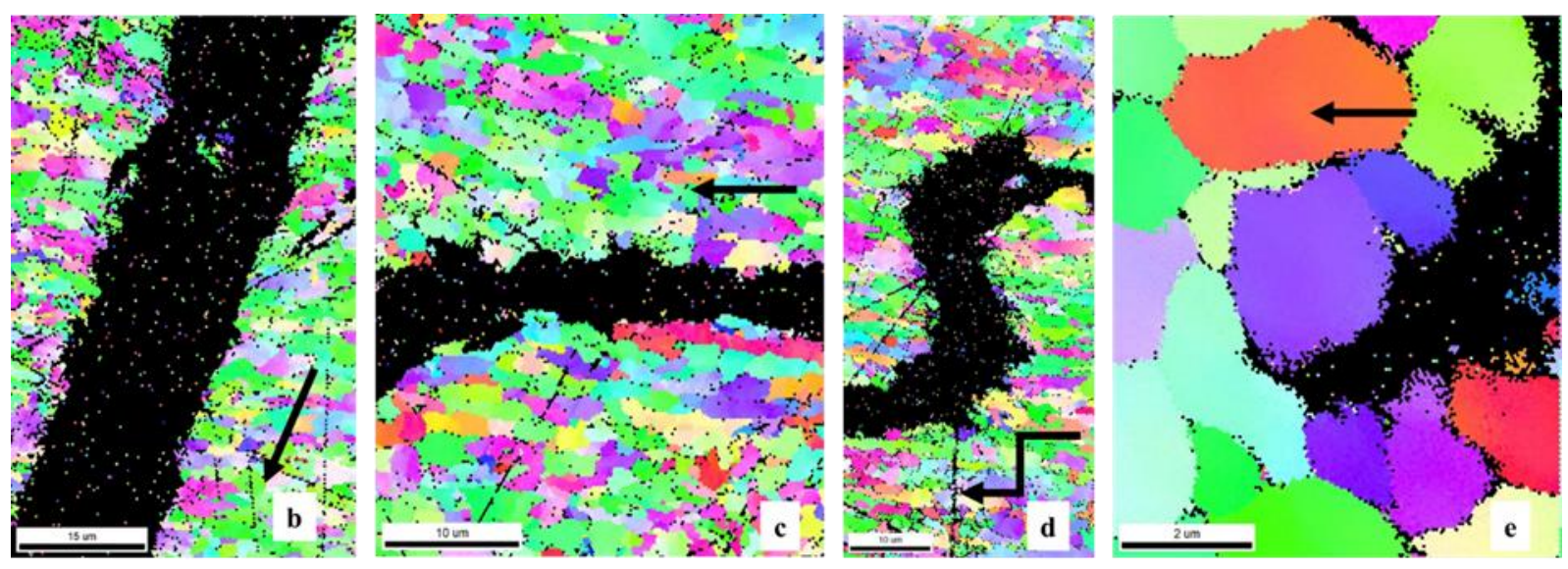

Figure 13: Result of EBSD analysis of precipitation hardening steel.

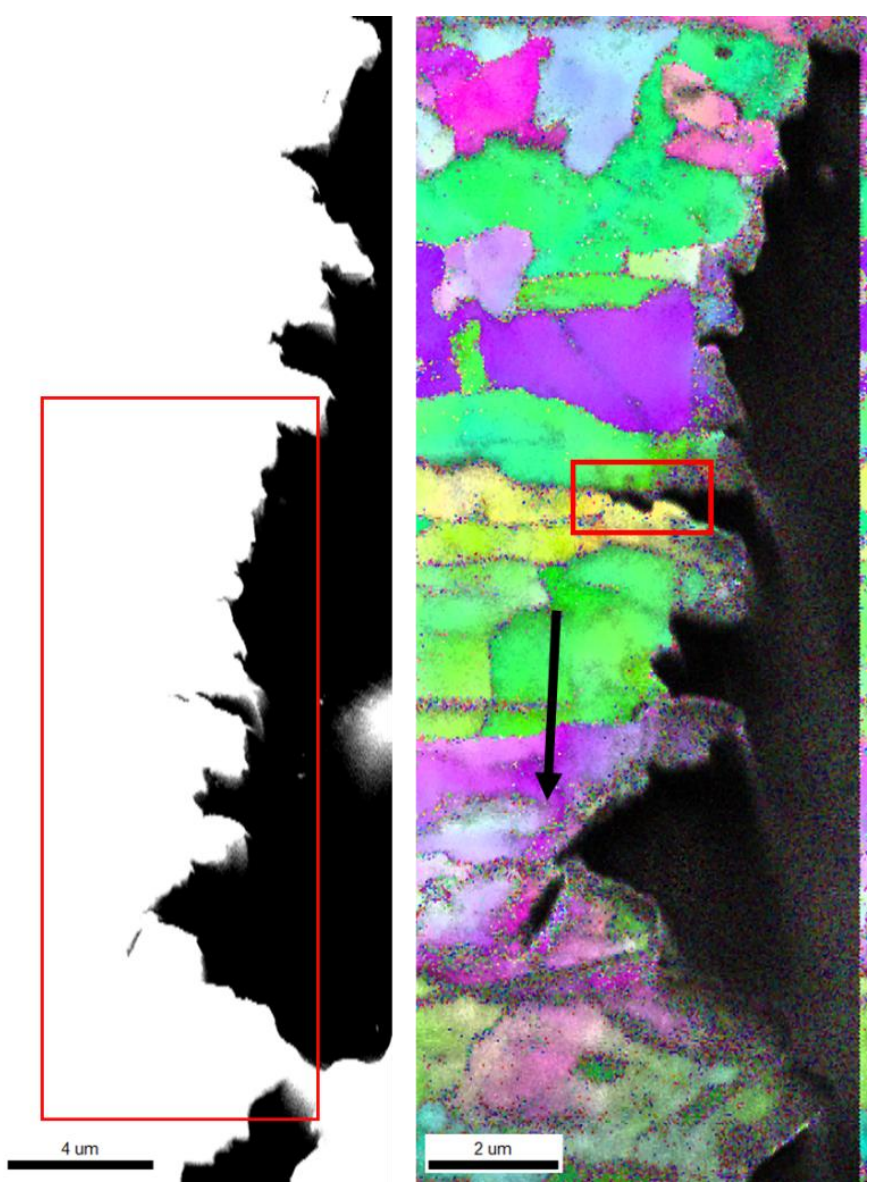

Figure 14: Result of EBSD analysis of precipitation hardening steel near point b.

\section{CONCLUSIONS}

$\mathrm{I}$

$\mathrm{n}$ this study, 4-point bending fatigue tests were performed for four types of steel plates with surface notch (590 MPa class current material, $980 \mathrm{MPa}$ class bainitic steel, martensitic steel, and precipitation hardening steel). The notch sensitivity of each steel specimen was evaluated in comparison to smooth plate specimens. In addition, SEM observations and EBSD analysis of the cracks growth and propagation patterns were conducted. The following conclusions were drawn: 
- The fatigue strength of all the $980 \mathrm{MPa}$ class steel plates were higher than that of 590 class steel plate. An almost equivalent fatigue strength was obtained for the martensitic steel and bainitic steel specimens; however, the fatigue strength of precipitation hardening steel was 100-150 MPa higher than either of these steels. Hence, the fatigue strength was considered to be influenced by the microstructural control technique.

- Based on the results of notch sensitivity evaluation, the descending sequence of the tested steel specimens shows similar values for the $980 \mathrm{MPa}$ class martensitic steel and $980 \mathrm{MPa}$ class bainitic steel specimens, which are higher than that of the $590 \mathrm{MPa}$ class steel. Meanwhile, the notch sensitivity of $980 \mathrm{MPa}$ class precipitation hardening steel is the lowest amongst all tested specimens. However, the obtained notch sensitivity values were lower than those obtained with cylindrical specimens.

- Crack initiation of precipitation hardened steel is later than the other steels since nano-sized precipitates prevents the movement of dislocation require to the crack initiation.

- Crack propagation speed was slowest in precipitation hardened steel, followed by bainitic steel, martensitic steel and $590 \mathrm{MPa}$ class steel, respectively. SEM observations confirmed that similar crack propagation patterns were detected in the $590 \mathrm{MPa}$ class steel, bainitic steel, and martensitic steel specimens. However, the crack of bainitic steel was intercepted by martensitic phase inside the steel, this phenomenon is considered to be the cause of delay in crack propagation. The fatigue crack formed in the precipitation hardening steel specimen showed quite different propagation pattern, with changes in the crack direction after approximately $500 \mu \mathrm{m}$ propagation.

- EBSD analysis revealed the different fatigue crack propagation patterns in each steel. In particular, the change in the fracture morphology of precipitation hardening steel from transgranular fracture into intergranular fracture was revealed.

\section{REFERENCES}

[1] Weixing, Y, Kaiqua, X. (1995). On the fatigue notch factor, Kf, Int. J. Fatigue, 17(4), pp. 245-251. DOI: 10.1016/01421123(95)93538-D

[2] Ishibashi, T. (1984). Kinzokuhirou to hakaino boushi, Yokendo. NCID: BA43331546/

[3] Yoshikawa, N., Kobayashi, J., Sugimoto, K. (2012). Notch-Fatigue Properties of Advanced TRIP-Aided Bainitic Ferrite Steels, Metallurgical and Materials Transactions A, 43(11), pp. 4129-4136. DOI: 10.1007/s11661-012-1246-x

[4] Riemer, A., Leuders, S., Thone, M., Rechard, H.A., Troster, T. Niendorf, T. (2014). On the fatigue crack growth behaviour in 316L stainless steel, Engineering Fracture Mechanics 120, pp. 15-25.

DOI:10.1015/j.engfracmech.2014.03.008.

[5] Nikulin, I., Sawaguchi, T., I Ogawa, K., Tsuzaki, K. (2016). Effect of $\gamma$ to $\varepsilon$ martensitic transformation on low-cycle fatigue behaviour and fatigue microstructure of Fe-15Mn-10Cr-8Ni-xSi austenitic alloys, Acta Materialia15, pp 207218. DOI: $10.1016 /$ j.actmat.2015.12.002.

[6] Krueger, D. D., Antolovich, S. D., Van Stone, R. H. (1987). Effects of grain size and precipitate size on the fatigue crack growth behavior of alloy 718 at $427^{\circ} \mathrm{C}$, Metallurgical Transactions A 18(8), pp. $1431-1449$.

DOI: $10.1007 / \mathrm{BF} 02636657$.

[7] Branco, C. M., Infante, V., Bapitista, R. (2004). Fatigue behavior of welded joints with cracks, repaired by hammer peening, Fatigue \& Fracture of Engineering Materials 27(9), pp. 785-798. DOI: 10.1111/j.1460-2695.2004.00777.x.

[8] Sidhom, N., Laamouri, A., Fathallah, R., Braham, C. Lieurade, H.P. (2005). Fatigue strength improvement of 5083 H11 Al-Alloy T-welded joint by shot peening: experimental characterization and predictive approach, International journal of fatigue 27, pp. 729-745. DOI: 10.1016/j.ijfatigue.2005.02.001.

[9] Yoshitake, A., Kinoshita, M., Osawa, K., Ogawa, K., Nakagawa, H., Kabasawa, M. (1994) pp. 1-2.

[10] Fatigue Properties of Fillet Welded Lap Joints of High Strength Steel Sheet for Automobiles, The Engeneering Society For Adbancing Mobility Land Sea Air and Space, 1994.

[11] Vallellano., C, Navarro., A, Dominguez., J. (2009). Fatigue failure assessment under stress gradients using small crack fatigue concepts, Engineering Failure Analysis 16, pp 2646-2657. DOI: 10.1016/j.engfailanal.2009.04.018.

[12] Okamura, H. (1976). Senkei hakai rikigaku nyumon, Baihukan, pp. 139, ASIN:B000JA0VDC. 